\title{
Interactive comment on "Integrated soil fertility management drives the effect of cover crops on GHG emissions in an irrigated field" by Guillermo Guardia et al.
}

\section{Anonymous Referee \#2}

Received and published: 13 June 2016

The topic of the manuscript (MS) is within the scope of Biogeosciences and it is generally well written and the results are presented clearly.

However, I have some issues, that need to be addressed by the authors:

1. To me this MS presents rather limited novelty to the study by Sanz-Cobena et al. (2014). Also the added $15 \mathrm{~N}$ approach brings nothing really new to the current knowledge. The authors should therefore elaborate more clearly the novel and innovative character of their research. 2 . What is rather "non-innovative" is the fact, that the cover crops are killed chemically with glyphosate. This is somewhat disappointing for research in agricultural sustainability, as the safe use of glyphosate is under discussion since years. There are alternatives in place also for Mediterranean regions

Printer-friendly version

Discussion paper 
and might be found among farmers applying organic no-till agriculture. The authors should address this topic in the discussion section, that the application of glyphosate for cover crop management is disputable and alternative measures to remove the cover crops with smart methods are needed (e.g. European project TILMAN-ORG) 3. Cover crop establishment: I am wondering that a hand broadcast technique is used for CC seeding. This might cause too many heterogeneities and influence yield-scaled N2O emissions. Please discuss. 4. The authors use too many and sometimes unnecessary abbreviations, please adapt. 5. Chambers for GHG sampling: I found it a bit too shallow to insert the stainless rings only $5 \mathrm{~cm}$ deep into the soil. There is a high risk of lateral $\mathrm{N} 2 \mathrm{O}$ emission, when the rings/collars are inserted not deep enough $(>10 \mathrm{~cm})$. Please explain.

\section{Recommendation: Major revision}

Interactive comment on Biogeosciences Discuss., doi:10.5194/bg-2016-29, 2016. 